\title{
Antifungal activity of Diphenyl Diselenide alone and in combination with itraconazole against Sporothrix brasiliensis
}

Vanice Rodrigues Poester ${ }^{1,2}$, Antonella Souza Mattei ${ }^{3}$, Josiara Furtado Mendes ${ }^{1}$, Gabriel Baracy Klafke ${ }^{1}$, Ivy Bastos

Ramis $^{2}$, Karine Ortiz Sanchotene ${ }^{1}$, Cristina Wayne Nogueira4; Gilson Zeni4; Tchana Martinez Brandolt ${ }^{1,2}$; Melissa Orzechowski Xavier ${ }^{1,2}$

${ }^{1}$ Mycology Lab, Faculty of Medicine, Federal University of Rio Grande (FaMed-FURG), Rio Grande do Sul, Brazil, ${ }^{2}$ Post-graduation program in Health Science, FaMed-FURG, RS, Braz ${ }^{3}$ University of Caxias do Sul, ${ }^{4}$ Post-graduation program in Toxicological Biochemistry, Federal University of Santa Maria (UFSM), RS, Brazil

melissaxavierfurg@gmail.com

\section{INTRODUCTION}

Given the currently importance of zoonotic sporotrichosis added to the promising antifungal effect of diphenyl diselenide $(\mathrm{PhSe})_{2}$ against a variety of fungal species, this study aimed to evaluate the in vitro susceptibility of Sporothrix brasiliensis to (PhSe) $)_{2}$ and to the combination of this compound with itraconazole (ITC).

40 clinical strains

of

S. brasiliensis

(20 from felines/

20 from human)

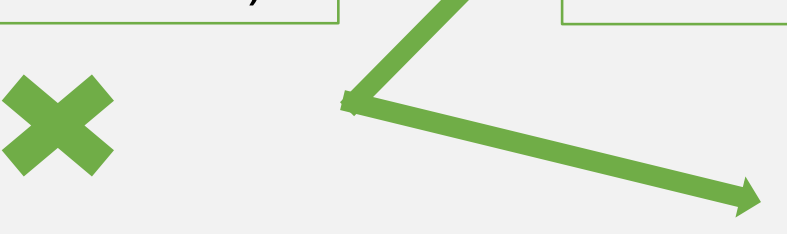

$(\mathrm{PhSe})_{2}: 0.25$ to $128 \mu \mathrm{g} / \mathrm{Ml}$

ITC: 0.0313 to $16 \mu \mathrm{g} / \mathrm{MI}$

\section{METHODS}

\section{Microdilution Technique}

(Clinical and Laboratory Standards

Institute protocol, M38 CLSI, 2008)

RESULTS

Table 1. Results of the microdilution test with diphenyl diselenide (PhSe) $)_{2}$ and itraconazole (ITC) against clinical isolates of $S$. brasiliensis $(n=40)$.

\begin{tabular}{|c|c|c|c|c|c|c|}
\hline Drug & \multicolumn{2}{|c|}{ Range of MICs $(\mathrm{GM})(\mu \mathrm{g} / \mathrm{ml})$} & \multicolumn{2}{|c|}{$\mathrm{MIC}_{50}(\mu \mathrm{g} / \mathrm{ml})$} & \multicolumn{2}{|c|}{$\mathrm{MlC}_{90}(\mu \mathrm{g} / \mathrm{ml})$} \\
\hline & Feline & Human & Feline & Human & Feline & Human \\
\hline$(\text { PhSe })_{2}$ & $4-32(10.93)^{\mathrm{a}}$ & $\begin{array}{c}4-32 \\
(13.45)^{\mathrm{a}}\end{array}$ & 8 & 16 & 32 & 32 \\
\hline ITC & $0.125-1(0.32)^{\mathrm{a}}$ & $0.125-1(0.42)^{\mathrm{a}}$ & 0.25 & 0.5 & 0.5 & 1 \\
\hline
\end{tabular}

MIC: minimum inhibitory concentration; GM: geometric mean; $(\mathrm{PhSe})_{2}$ : diphenyl diselenide; ITC: itraconazole. Different small letters correspond to $p<.05$ for the MIC values comparison between strains origin (columns) (Kwtest).

Table 2. Results of the checkerboard test with diphenyl diselenide ( $\mathrm{PhSe})_{2}$ and itraconazole (ITC) against $S$. brasiliensis $(n=40)$, determining the index of the fractional inhibitory concentration $(\mathrm{FICI})$.

\begin{tabular}{|c|c|c|c|c|c|}
\hline & $\begin{array}{c}\text { FICI } \leq 0.5 \\
\text { Synergistic }\end{array}$ & $\begin{array}{c}0.5<\mathrm{FICl} \leq 1 \\
\text { Additive }\end{array}$ & $\begin{array}{c}1<\mathrm{FICI} \leq 4 \\
\text { Indifferent }\end{array}$ & $\begin{array}{c}\mathrm{FICI}>4 \\
\text { Antagonist }\end{array}$ & Total \\
\hline Feline & 0 & 15 & 5 & 0 & 20 \\
\hline Human & 3 & 11 & 6 & 0 & 20 \\
\hline Total & 3 & 26 & 11 & 0 & 40 \\
\hline
\end{tabular}

$73 \%$

$(29 / 40)$

\section{CONCLUSION}

Diphenyl diselenide showed a promising in vitro activity against $S$. brasiliensis. In addition, the high percentage of positive effects $(73 \%)$ in $(\mathrm{PhSe})_{2}$ combination with itraconazole, suggest that it also has a further potential as an adjuvant therapy with antifungal agents. 